\title{
UMA MORTE MUITO EXAGERADA: ROBIN G. COLLINGWOOD E A “ROMANIZAÇÃO” DA BRETANHA ROMANA
}

Renato Pinto ${ }^{1}$

\begin{abstract}
Resumo
Robin G. Collingwood é considerado o grande pesquisador dos estudos romano-bretões no período entreguerras. Suas contribuições neste campo, ainda que menos famosas do que seus trabalhos na Filosofia da História, lograram inserir a Bretanha Romana na história Britânica, e trouxeram, a reboque, uma abordagem interpretativa única que alinhavava conceitos filosóficos e históricos às suas pesquisas arqueológicas sobre o fenômeno da "Romanização" das províncias romanas. Sua crença na inevitabilidade do preconceito do estudioso ao se aproximar de seu objeto e na necessidade e possibilidade deste de recriar o passado em sua mente, no presente, rendeu-lhe uma espécie de renascença bibliográfica na produção arqueológica pós-processual. De alguma forma conectada a isso, sua concepção da "Romanização", ainda que rígida, mostra-se indelével à crítica epistemológica do termo no pós-colonialismo britânico. O legado de Robin Collingwood costuma oscilar entre o reverencial e o ridículo, algo que só reforça a importância de tais movimentos tão longevos.
\end{abstract}

\section{Palavras-chave}

Robin G. Collingwood; Bretanha romana; romanização.

\footnotetext{
1 Professor Doutor, Universidade Federal de Pernambuco, Recife, Brasil. E-mail: tdhm@uol.com.br
} 


\begin{abstract}
Robin G. Collingwood is considered the great researcher of RomanoBritish studies in the interbellum period. His contributions in this field, although less famous than his works in the Philosophy of History, succeeded in inserting Roman Britain into British history, and brought in tow a unique interpretative approach that weaves philosophical and historical concepts with his archaeological research on the phenomenon of the "Romanisation" of the Roman provinces. His belief in the inevitability of the scholar's prejudice in approaching his object and in his/her need and possibility to recreate the past in his/her own mind, in the present, has given Collingwood a kind of bibliographic renaissance in post-processual archaeological production. Somehow connected to this, his conception of "Romanisation," however rigid, is indelible to the epistemological critique of the term in British postcolonialism. Collingwood's legacy usually oscillates between the reverential and the ridiculous, something that only reinforces the importance of such longlived movements.
\end{abstract}

\title{
Key-words
}

Robin G. Collingwood; Roman Britain; romanisation. 


\section{Introdução}

Fui primeiro apresentado aos estudos sobre a Bretanha Romana (opto aqui por essa forma, em vez de Britannia ou mesmo Britânia) e sua "Romanização" (termo polêmico e por isso, aqui, aspeado) por Pedro Paulo Funari, ao final da década de 1990. Mas seus trabalhos sobre a presença das ânforas béticas em Vindolanda remontam ao início da década (Funari, 1991). Logo depois, publicou importante e influente arrazoado a respeito dos estudos da Bretanha Romana na Revista de História da Arte e Arqueologia (1994). Suas pesquisas e publicações sobre a província romana seguem relevantes e inovadoras. Meu mestrado e doutorado, que tratam de temas ligados diretamente aos discursos da "Romanização" da Bretanha Romana, foram frutos de seu pioneirismo, de sua inspiração, e de sua preciosa orientação. Este pequeno artigo, que coteja algumas breves reflexões acerca das pesquisas romano-bretãs desenvolvidas por Robin Collingwood na primeira metade do séc. XX, tem o principal propósito de homenagear o grande pesquisador e mestre que é Pedro Paulo Funari. Espero que sirva, ainda, como uma introdução à epistemologia do tema da "Romanização" da Bretanha Romana.

\section{R. G. Collingwood}

Robin George Collingwood (1889 - 1943), filósofo, historiador e arqueólogo inglês, tornou-se o acadêmico mais famoso em sua família, já envolvida com artes e departamentos de História e Arqueologia antes dele. R. G. Collingwood foi educado na Rugby School e tornou-se professor da Universidade de Oxford. Foi, e ainda é considerado por muitos um idealista, embora ele mesmo jamais tivesse aceitado tal rótulo. De fato, no início de sua carreira acadêmica, ao menos até 1916, Collingwood esteve ao lado de estudiosos autointitulados realistas, especialmente E.F. Carritt e John Cook Wilson. Progressivamente, foi se afastando do realismo e aproximando-se de figuras idealistas expoentes da Filosofia europeia, como Benedetto Croce. Suas maiores influências, além da de Haverfield, foram seu pai, William G. Collingwood, Kant, Ruskin e autores italianos idealistas como Croce e Gentile. Em 1913 Collingwood publicou uma tradução para o inglês de Croce, e viria a traduzir muitos outros trabalhos tanto de Croce quanto de Giovanni Gentile. Seus trabalhos em Arte e Estética marcaram a época, também (Ridley, 2001). Contudo, foi no campo da Filosofia e da História, e na defesa da aproximação dessas duas disciplinas, que Collingwood mais se destacou. Collingwood foi o único aluno de Francis J. Haverfield (tratado 
mais abaixo) que sobreviveu à Primeira Guerra Mundial, onde serviu no setor de inteligência naval. Para muitos, é ele o verdadeiro herdeiro acadêmico de Haverfield (Hingley, 2000: 131). Na Arqueológica, Collingwood dedicou-se a estudar, principalmente, os assentamentos romanos da Bretanha Romana e a questão da "romanização" em obras como Roman Britain, The Archaeology of Roman Britain e Roman Britain and the English Settlements (esta última em parceria com J. N. L. Myres, mas com contribuições em separado no volume). A partir de 1912, Collingwood participa ativamente com Haverfield em escavações arqueológicas de sítios romanos no norte da Inglaterra. Embora dissesse que a Arqueologia era para ele apenas um hobby, Collingwood foi para sua época uma autoridade também nessa área de pesquisa, produzindo centenas de trabalhos sobre a Bretanha Romana e sobre o que julgava ser a herança cultural romana deixada à Inglaterra após o séc. V d.C. Mais tarde, focaria suas atenções na Filosofia e suas palestras geraram uma de suas obras póstumas: The Idea of History. Publicada postumamente por seu aluno T. M. Knox, a obra tornou-se referência para a Filosofia da História no pós-guerra. Durante sua viagem à Ásia, entre 1938 e 1939, começou a escrever a obra que julgava ser seu maior feito: The Principles of History, só publicada muito mais tarde, ao fim do séc. XX. Quando de seu retorno a Oxford, Collingwood, preocupado com o avanço das ideias nazistas e fascistas e com os efeitos políticos e morais da Segunda Grande Guerra, escreveu The New Leviathan. Neste momento de grande instabilidade mundial, Collingwood assume visões políticas que destoam de muitos de seus colegas de Academia, que tendiam a ser ainda adeptos à sobrevivência do projeto colonizador europeu. Depois de sua viagem às colônias holandesas na Ásia, parece ter claro em sua mente que a neocolonização ocidental poderia também trazer consequências nefastas aos países colonizados (Collingwood, 1923: 14; Hingley, 2000: 131-2) e que o contraste entre ricos e pobres era uma ofensa ao ideal de civilidade que se almejava. Para Collingwood, o uso da força do mais rico para acumular riquezas que somente destacavam as diferenças entre ricos e pobres é sintoma da busca pela destruição de civilizações ou pelo barbarismo (Collingwood, 1942: 38 e 74, 82-83). ${ }^{2}$

Pode-se argumentar que foi a questão da interpretação e definição do que é o passado pela Arqueologia pós-processual que trouxe a abordagem de Collingwood de volta à tona (Whitley, 1998a: 179; Renfrew \& Bahn,

\footnotetext{
2 As informações biográficas de R. G. Collingwood apresentadas aqui foram coletadas, salvo quando outros autores são citados, a partir do site da Stanford Encyclopedia of Philosophy no seguinte link: http://plato.stanford.edu/entries/collingwood/. Acessado em 20/11/2017.
} 
2005b: xi; e 2005: 41). A ênfase que os trabalhos de Collingwood deram à compreensão do passado por meio do pensamento, e não de métodos empíricos, fez dele uma influência significativa ao debate teórico pósprocessual em torno de como Arqueologia e História podem trabalhar juntas na interpretação cognitiva de sociedades extintas (Whitley, 1998a: 179-80). Embora não se possa elencar com toda convicção quais são as, potencialmente, múltiplas motivações para o ressurgimento das ideias de Collingwood na literatura arqueológica pós-moderna, no contexto de um importante segmento da disciplina que adota teorias e métodos mais subjetivos para entender o passado, não é difícil supor porque Collingwood é visto como uma figura emblemática. Dentre os grandes motivos para o renovado interesse em estudar suas concepções pode estar o fato de Ian Hodder, ele próprio um símbolo do movimento pósprocessual, ter buscado sua inspiração idealista na forma como Collingwood defendia que o passado deveria ser interpretado (Cobb, 1998: 201). Não haveria como explorar, neste espaço, com verticalidade, as teorias de Collingwood sobre a interpretação do passado, mas apresento agora algumas nesgas de suas formulações.

\section{A "empatia" e o "ressurgimento" de Collingwood}

O ponto mais polêmico da teoria de Collingwood sobre o passado diz respeito à empatia entre a mente do pesquisador e aquela do sujeito por ele estudado, por intermédio dos artefatos escavados. Collingwood postulava que o historiador seria capaz de recriar o passado e compartilhar do mesmo pensamento do indivíduo estudado:

O historiador deve reviver o passado em sua própria mente ... Quando um homem pensa historicamente, ele tem diante dele certos documentos ou relíquias do passado. Seu ofício é descobrir o que foi o passado que deixou tais relíquias para trás ... Isso significa descobrir o pensamento ... expressado [por elas]. Para descobrir o que foi esse pensamento, o próprio historiador deve pensá-lo novamente (Collingwood, 1946: 282-3; ênfase no original. Apud Whitley, 1998: 179-80). Trad. do autor.

Assim, Collingwood acreditava que o passado histórico deveria ser reconstruído no pensamento do presente (Collingwood, 1946: 293), mutatis mutandi, uma ideia também compartilhada por muitos arqueólogos pós-processuais (Shanks \& Tilley, 1992: 14-5 e Shanks \& Hodder, 1998: 78; Hills 2005: 140) e historiadores tidos como pósmodernos (Jenkins, 1991: 12), algo de que tratarei mais abaixo. 
As pressuposições do investigador são, também, outra área de interesse pós-processual (Shanks \& Hodder, 1998: 82-3) que pode ser encontrada em Collingwood. Collingwood argumentava que todo estudioso do passado faz, de uma forma ou de outra, algum juízo de valor quando se aproxima de seu tema. De fato, sem esse pré-conceito, não haveria História (Collingwood, 1999: 217), pois é justamente esse julgamento do historiador que o faz selecionar, entre uma miríade de coisas que se passaram, o seu objeto de estudo. Na concepção de Collingwood, toda investigação histórica começa com um preconceito (Idem: 213), que nada mais seria do que "um desejo de descobrir que determinada resposta a uma questão feita por alguém é a correta (Ibidem: 210)".

\section{O fenômeno seria inevitável}

Em vez de nos lisonjearmos hipocritamente de não termos preconceitos, ou tentarmos, em vão, nos livrar deles, devemos examinar nossas próprias mentes e descobrir quais são nossos preconceitos. Podemos estar certos de que existem; muito bem, descubramos quais são e nos disciplinemos a fim de dar especial atenção às evidências em favor de pontos de vista contrários aos nossos preconceitos (Id.Ibidem: 212). Trad. do autor.

O leitor poderia, então, estar a par de quais são os preconceitos que afetam o investigador, que deles não deve fazer segredo (Id.Ibidem: 213). ${ }^{3}$ Para Collingwood, o historiador deve também conceder que o conhecimento é fruto de suas perguntas feitas ao objeto de estudo. $\mathrm{O}$ questionamento é a alma do conhecimento, ao passo que a informação é apenas seu corpo. No entanto, enquanto as respostas podem se modificar, sendo essas continuamente revisadas, as perguntas permanecem intactas (Collingwood, 1924b: 78 e 80). ${ }^{4}$

Como já foi dito, Collingwood é conhecido por sua proposta de estudar o pensamento e não as ações e, ao fazer uma clara distinção entre Naturwissenschaften e Geisteswissenschaften, defende que o papel da História não é estudar o ser humano na sua natureza, ou seja a "história

\footnotetext{
${ }^{3}$ Em uma aproximação com a literatura moderna, Shanks e Hodder também abordam a questão dos 'preconceitos' do "intérprete" (arqueólogo), chegando a afirmar que, além de benéficos, são o meio adequado para se alcançar a "real" e "objetiva" compreensão do que estudamos (Shanks \& Hodder, 1998: 82-3).

${ }^{4}$ Há ainda um curioso paralelo moderno na ênfase ao uso da hermenêutica (na forma de perguntas e respostas, em linhas gerais) em Shanks \& Hodder (1998: 83).
} 
natural", já que a palavra "história" não reflete nosso interesse na evolução do homo sapiens, mas, antes, nas pessoas como seres civilizados. Em Collingwood, a História tem de dar conta do estudo da mente, criada e gerida por processos racionais:

(...) muitas coisas que preocupam profundamente os seres humanos não são, e nunca foram, tradicionalmente incluídas na disciplina História. As pessoas nascem, comem e respiram e dormem, geram crianças, ficam doentes e se recuperam novamente, e morrem; e essas coisas lhes interessam, a maioria delas, de qualquer forma, muito mais do que a arte e a ciência, os negócios e a política e a guerra. No entanto, nenhuma dessas coisas tem sido tradicionalmente considerada como possuidora de interesse histórico. A maioria delas deu origem a instituições como jantar e casar e aos vários rituais que cercam o nascimento e a morte, a doença e a recuperação; e a respeito desses rituais e instituições as pessoas escrevem histórias; mas a história do jantar não é a história do comer, e a história dos rituais da morte não é a história da morte (Collingwood, 1999: 46). Trad. do autor.

Desta feita, o "homem animal” não interessa à História. Ela procurará dar conta do estudo da mente, da sensibilidade, elementos criados por processos racionais, como a linguagem e a semântica, que criam símbolos variantes para explicar o mundo (Veyne, 1982: 12-3). Essa linguagem foi diversa daquela do presente, nos múltiplos contextos socioculturais do passado, fazendo dele (passado) um território estrangeiro (Jenkins, 1991: $43)$.

Ainda:

(...) [a chamada Res Gestae] não são as ações, no sentido mais amplo dessa palavra, que são feitas pelos animais da espécie chamada humana; são ações em outro sentido da mesma palavra, igualmente familiar, mas mais estreita, ações feitas por agentes razoáveis em busca de fins determinados por sua razão (Collingwood, 1999: 46). Trad. do autor.

Collingwood aponta que, a fim de entender o passado historicamente, o historiador não formulará hipóteses empíricas. Antes, deve, e pode reconstruir o pensamento do indivíduo do passado porque o pensamento é um fenômeno que não se restringe ao agente em um dado momento histórico. Ele (o pensamento) é, em princípio, público e pode ser 
reencontrado. ${ }^{5}$ É desta forma que Collingwood explica como aborda o pensamento de Platão, por exemplo:

(...) à sua época, enquanto uma experiência real dele mesmo, o argumento de Platão deve, sem dúvida, ter se desenvolvido a partir de uma discussão de algum tipo, embora eu não saiba qual, e estava intimamente ligado a tal discussão. No entanto, se eu não apenas leio seu argumento, mas o compreendo, acompanho-o em minha própria mente reencenando-o comigo e para mim mesmo, o processo do argumento pelo qual eu passo não é um processo que se assemelha ao de Platão, na verdade é o de Platão, desde que eu o compreenda corretamente (Collingwood, 1946: 301). Trad. do autor.

Assim, a compreensão histórica se dá quando o historiador experimenta o mesmo processo de pensamento pelo qual passou a personagem histórica que ele ou ela investiga (Renfrew, 2005: 41). O prestígio que Collingwood adquiriu na Filosofia da História lhe garantiria neste campo de conhecimento uma audiência esperada na primeira metade do séc. XX e seus trabalhos na Arqueologia abririam a possibilidade de serem aplicadas suas mesmas premissas teóricas aos estudos da cultura material. $\mathrm{O}$ inesperado, todavia, é seu ressurgimento nas teorias interpretativas arqueológicas ao final do mesmo século. A receptividade e certa reverência às suas ideias a respeito da reconstrução do passado pela mente por alguns arqueólogos ainda causam certa surpresa. ${ }^{6}$ A polimatia dos trabalhos publicados por Collingwood ao longo de sua vida engendrou diversas conexões entre campos do conhecimento hoje mais demarcados, em especial, entre Filosofia, História e Arqueologia, em uma dinâmica em larga medida retroalimentar. Os anos 1990 veriam uma rediviva aproximação teórica entre História e Arqueologia e o que ocorreu ulteriormente a tal "reencontro" foi o ressurgimento de nomes de alguns antigos historiadores e filósofos da História, oriundos do século $\mathrm{XX}$, nas publicações arqueológicas pós-processuais, como inspiração ou parâmetro para a abordagem de sociedades do passado, especialmente aqueles autores cujas obras apoiavam inferências e/ou investigações alinhadas com as subjetividades envolvidas na reconstrução do passado; ou ainda, aqueles que haviam desenhado e proclamado a natureza narrativa do documento com a fórmula "questões-problemas-respostassoluções", como as teorias da long durée dos Annales (Peebles 1998: 189). É

\footnotetext{
${ }^{5}$ Essa proposição parece ser mais conceitual do que metodológica no trabalho de Collingwood.

6 Contudo, essa aparente capacidade "telepática" do investigador não deixa de ser desacreditada por alguns (Jenkins, 1991: 39) ou mesmo ridicularizada por outros, especialmente, mas não somente, quando sugerida aos estudos de Pré-História (Kohl 1997: 17a; Gilman, 1987: 516; Renfrew, 2005: 41-2).
} 
neste cenário que os nomes de R. G. Collingwood, Braudel e Bloch reemergem nas bibliografias arqueológicas modernas (Funari 1998: 10; Whitley, 1998a: 179-80; Renfrew \& Bahn, 2005b: xi e 2005: 41). Neste trabalho, preocupado com os primeiros momentos da Arqueologia, o holofote está dirigido a R. G. Collingwood, e não aos Annales, uma vez que Collingwood esteve integrado tanto a História quanto a Arqueologia, e porque sua busca por uma melhor interpretação do passado ocorreu no que foi o período de origem da Arqueologia, academicamente falando. ${ }^{7}$ Ao início do séc. XX, Collingwood já meditava sobre a natureza epistemológica da Arqueologia, seu posicionamento oscilante entre a ciência empírica e as humanidades, um debate que só se agudizou na academia a partir da década de 1960 (Renfrew \& Bahn, 2005b: xi). Será, em particular, na chamada Arqueologia Cognitiva que as ideias de Collingwood encontrarão maior acolhida. Neste campo, grosso modo, o esforço do arqueólogo se direciona a encontrar o pensamento dos criadores e usuários dos artefatos do passado, mais especificamente, na recriação de seus significados, por meio das análises de suas simbologias, e no questionamento adequado a eles dirigidos. Em última instância, há uma busca pela compreensão do funcionamento das mentes por trás dos artefatos. Ainda que o idealismo desse "entrar-na-mente" esteja hoje fadado ao ceticismo, a busca pelos significados é o grande objetivo da Arqueologia interpretativa, ou pós-processual, surgida ao final dos anos 1980. É neste contexto teórico-metodológico que são observados os grandes paralelos com os trabalhos filosófico-teóricos da hermenêutica de Collingwood, portanto (Renfrew, 2005: 41; Wylie 1997: 24b; ver, ainda, Peebles 1998). Nem tudo de Collingwood é reaproveitado no pósprocessualismo, lógico, e seu próprio contexto histórico importa. Falamos aqui muito mais de ressignificações. Qualquer adoção de teorias do passado ou do presente passa por filtros que cercam o estudioso, seja ele arqueólogo ou historiador (Jenkins, 1991: 19) e, assim, é apenas razoável pensar que as ideias de Collingwood foram reconstruídas subjetivamente por aqueles que delas fizeram e ainda fazem uso. É preciso avaliar como discursos colonialistas do Império Britânico de então afetaram a formação das ideias de Collingwood, sua forma de ver o passado, por exemplo, e como alguns de seus preceitos chegaram até os debates arqueológicos do pós-processualismo.

O "renascimento" de Collingwood na teoria arqueológica foi muito mais energético do que a sobrevivência de seus estudos de campo, propriamente ditos. No entanto, suas publicações sobre a Bretanha

\footnotetext{
7 Para um olhar mais detalhado do uso da Escola dos Annales e seu 'consumo' pela Arqueologia pós-processualista, ver Chippindale 1997: 34a/b e 35a e Cobb 1998.
} 
Romana e sua "romanização" têm um peso que não pode ser ignorado. A seguir, tratarei brevemente dessa questão.

\section{A “Romanização" da Bretanha Romana}

O processo de expansão territorial e cultural de Roma sobre as províncias, em especial no Principado, conhecido na literatura moderna como "Romanização" figura há um bom tempo nos trabalhos de arqueólogos e/ou historiadores imbuídos em buscar explicações ao avanço do Império Romano e, do mesmo modo, à pressuposta absorção da cultura e da identidade romanas. Convencionalmente, de acordo com as abordagens tradicionalistas, a adoção da cultura material subentendida como "romana" permitiria mensurar o quão "romanizadas" estariam as províncias. Quanto mais intensa se tornasse a presença de artefatos "romanos" e "romanizados", maior seria a transformação cultural, e, no limite, identitária (Grahame, 1998: 175). Desde o final dos anos 1980, essa conexão linear entre cultura material e identidade não passou incólume às críticas da geração pós-colonialista e, assim, muitos arqueólogos e historiadores relutam em aceitar a imediata ligação entre a presença da uma cultura material tida como "romana" com qualquer sugestão de identidade romana, ou mesmo, ainda, qualquer sinal de baixa resistência aos conquistadores (Grahame, 1998: 150 e 158; Siân Jones, 1997: 114-5 e 133-4; 1999: 220-1). A geração oxfordiana de arqueólogos e historiadores do início do séc. XX que influenciou Collingwood e seus trabalhos subsequentes teve grande impacto no desenvolvimento e difusão do conceito de "Romanização". Traçar as origens precisas do fenômeno pode ser uma quimera, mas caberia argumentar que os contornos mais precisos do debate no meio acadêmico podem primeiro ser observados a partir de Theodor Mommsen (1817-1903), historiador e estudioso do direito, que propagou a teoria do "imperialismo defensivo" de Roma. Em 1854, Mommsen publicou uma obra abrangente sobre a República romana, e o paralelo com a situação política de 1848 e as unificações da Itália e da Alemanha foi perceptível. ${ }^{8}$ Para ele, certas instituições romanas, como a cidadania, o latim, cunhagem de moedas etc, poderiam ser mensuradas a fim de que a intensidade da adoção da cultura romana pelas províncias pudesse ser estabelecida (Freeman, 1997: 31). Mommsen logrou ter suas ideias difundidas em Oxford, lá inseridas por meio de Henry Pelham (1846-1907). No entanto, foi Francis Haverfield (1860-1919), o sucessor

\footnotetext{
8 Freeman considera que a obra de Mommsen, Römische Geschichte (1854), pode ser comparada a um panfleto político (Freeman, 1997: 30).
} 
acadêmico de Pelham, quem acabou por integrar os estudos sobre a "romanização" da Bretanha Romana àqueles do resto da Europa, fomentando a percepção de que teria havido um Império Romano homogêneo (Freeman, 1997: 37). Haverfield incorporou a epigrafia e outros dados arqueológicos à análise da "Romanização" e, assim como já havia feito antes Henry Pelham, buscou no passado romano certas práticas que possuíssem paralelos em seu tempo. Para Haverfield, "obcecado pela crença na descendência comum de todos os povos europeus, o registro arqueológico poderia mostrar tal hegemonia cultural em todo o Império Romano" (Pinto, 2016: 62; ver também Hingley 1996: 39; 1997: 83).

Collingwood concebia a "Romanização" como um processo que afastou os bretões de uma vida selvagem, rústica, da selvageria dos sacrifícios humanos, da imersão nos áreas pantanosas da ilha. Para ele, os romanos dominaram a região, lá impuseram seu jugo e sua civilização e, quando saíram, no início do século $\mathrm{V}$ d.C., deixaram para trás uma terra novamente entregue à barbárie celta. Contudo, Collingwood procura mostrar que os bretões que "ficaram para trás", não eram mais aqueles que os romanos haviam encontrado quase quatrocentos anos antes. Aqueles bretões estavam agora "romanizados". Assim, para Collingwood, houve uma clara continuidade cultural entre o período romano e o anglo-saxão, ainda que parcial (Collingwood, 1923: 11-2 e 978). A questão de fundo étnico-cultural é inescapável e complexa. Para Collingwood, a união da cultura romana e celta criou uma outra cultura, amalgamada, harmoniosa. Algo que ele compreende ser impossível no caso de britânicos e indianos. Em Collingwood, essas culturas estarão para sempre separadas, e jamais poderão gerar uma cultura resultante (Collingwood, 1932: 144). No que podemos crer ser um reflexo de seu sentimento antinazista e antifascista, Collingwood procura mostrar que os povos celtas da Bretanha Romana, mesmo após séculos de "romanização", nada tinham das características físicas italianas ou germânicas (Collingwood, 1937: 185).

Ao longo do último século, uma série de trabalhos buscou abordagens alternativas àquelas de Haverfield e Collingwood. ${ }^{9}$ Recentemente, as

\footnotetext{
9 Em 1990, o arqueólogo Martin Millett publicou The Romanization of Britain, onde procurou dar uma visão diferente daquilo que considerava ser uma abordagem paternalista dos estudos da Bretanha Romana, tendo como alvo Brittannia de S.S. Frere, escrito em 1967, e Roman Britain (1984), de Peter Salway, primeira edição de 1981. Millett argumentou que seu estudo trazia uma abordagem distinta, criada em um momento no qual o Império Britânico não era mais uma realidade, ao menos não tanto quanto o fora à época em que Frere e Salway desenvolveram suas principais pesquisas
} 
principais críticas da literatura arqueológica estão no uso do discurso político nacionalista que existe por trás do termo 'romanização', comparando-o a um ideal imperialista contemporâneo, onde a maioria das explicações sobre o imperialismo romano estaria por demais ancorada. Nossas fontes documentais antigas seriam afetadas por esse discurso específico, e sua interpretação é feita no bojo de uma bagagem ideológica ligada às noções do imperialismo do séc. XX. Com cada vez mais intensidade, pesquisadores vindos de países colonizados têm denunciado essa influência e tecido críticas severas à disseminação de um discurso político sectário bem marcado pelo colonialismo (Mattingly, 1997: 14-7; Siân Jones, 1997: 129-30; Hingley, 2000: xiv). Na década de 1990, o conceito de "Romanização" começou a ser estudado como "aculturação"10, uma troca dialética que, ainda assim, apenas reflete uma abordagem pós-colonialista aos mesmos critérios interpretativos de Francis Haverfield. É possível constatar que conceitos complexos como poder, riqueza, idade, gênero, identidade étnica etc. não estão contemplados em "Romanização", fazendo dela um termo discursivo intrinsecamente excludente e inadequado (Hingley, 1996: 44-5; 1997: 85).

Não restam dúvidas de que Francis Haverfield foi o grande impulsionador dos estudos romano-bretões no início do séc. XX. Mas seus conceitos foram, em grande medida, marginalizados na academia (Freeman, 2007: 536). A figura de Collingwood é um marco nos estudos romano-bretões e sua "romanização", e teria sido a morte de Haverfield, em 1919, o grande fator que alçou Collingwood à eminência nos estudos

(Millett, 1990: xv-xvi). Salway, por sua vez, historiador, já havia escrito Roman Britain para substituir Roman Britain And The English Settlements, de Collingwood e Myres (1937).

10 Um dos primeiros estudiosos a definir "Aculturação" foi Melville J. Herskovits (1895-1963), professor de Antropologia da Northwestern University e fundador do primeiro programa de estudos africanos nos Estados Unidos. Seus trabalhos ajudaram a quebrar os ditames racistas propugnados por muitos intelectuais europeus e americanos até a Segunda Guerra Mundial. Em sua obra The Myth of the Negro Past (1941), aculturação foi definida, em termos genéricos, como os "estudos daqueles fenômenos que surgem quando grupos de indivíduos que possuem diferentes culturas entram em contato contínuo pela primeira vez, com subsequentes mudanças nos padrões culturais de um ou ambos os grupos (Herskovits, 1941: 10)." Apesar da prontidão em apontar para a possibilidade de mútuo processo de mudança cultural, o uso do termo na Antropologia e em outras Ciências Humanas indica que há uma marcada tendência em ressaltar a influência unidirecional do fenômeno. Assim, aculturação tem sido associada à ideia de que uma cultura considerada superior dominaria outra, inferior. Os cenários para tais análises são enviesados e incluem desde o domínio romano sobre as províncias ocidentais e o impacto do Ocidente sobre as nações denominadas de Terceiro Mundo (Miller, 1997: 244). Esta nota, na sua integralidade, encontra-se em Pinto, 2016: 103, n. 44). 
de tal sorte. Collingwood foi um dos poucos alunos de Haverfield que sobreviveram à Primeira Grande Guerra e acabou por assumir (não de todo relutante) a responsabilidade de dar continuidade ao projeto do Roman Inscriptions of Britain (RIB) (Collingwood \& Wright, 1965). Haverfield pretendia fazer um compêndio epigráfico da Bretanha que pudesse superar as falhas que via na sétima edição de outro vasto corpus de inscrições epigráficas latinas, iniciado e desenvolvido por Mommsen, no séc. XIX, o Corpus Inscriptionum Latinarum (CIL) (Freeman, 2007: 539). Apesar de ter assumido o lugar de Haverfield, Collingwood parecia preferir ser visto muito mais como um filósofo e historiador do que como um arqueólogo. Durante os primeiros anos de sua produção, de 1912 até 1925, Collingwood focou sua atenção quase que exclusivamente na Arqueologia. Entre 1925 e 1933, seu olhar começou a se voltar à filosofia da História, enquanto a Arqueologia passava por certa negligência. A partir de 1933, as publicações de Collingwood tomam um rumo quase que puramente filosófico (Freeman, 2007: 537-540). Não obstante, seu apreço pela Filosofia já era demonstrado nos seus primeiros trabalhos arqueológicos. De fato, Collingwood criticava com frequência Haverfield por este negligenciar a filosofia em suas pesquisas arqueológicas (Freeman, 2007: 543). Mas esta não era nem de perto a única crítica que Collingwood dispensava a Haverfield. Em uma resenha de palestras de Haverfield sobre a ocupação romana, assim falava Collingwood das conclusões deste a respeito do alcance da "Romanização":

Haverfield tendia a exagerar tanto o grau quanto a extensão desta Romanização: menosprezar o quanto a cultura romano-bretã, mesmo quando esta era mais romana, continuou bretã, e a superestimar os efeitos que teve nas camadas mais pobres da população. Na ponta da escala, os habitantes das vilas em todas as partes da província foram mesmo afetados pela civilização romana, mas não profundamente; e os hábitos de vida que revelam continuaram a mostrar elementos profundamente não-romanos. De fato, Haverfield não esteve cego para isso; ao contrário, ele frequentemente chamava a atenção para esse fato; contudo, no interesse de apresentar um ponto legítimo e importante, menosprezava isso, deixando uma impressão de não ver nada mais na cultura romano-bretã além do elemento romano. (Collingwood, 1924a: 436. Apud Freeman, 2007: 544. Trad. do autor).

Numa espécie de rompimento com a principal argumentação de seu antigo tutor, Collingwood reforçava a necessidade de reconhecer a enorme oscilação e discrepância na distribuição da "romanização" na ilha, em contraste ao que percebia ser uma homogeneização por parte de Haverfield. Quanto à forma como Haverfield podia, por vezes, supervalorizar suas interpretações, não deixa de ser irônico que seja 
justamente essa a mesma e maior crítica que os próprios trabalhos de Collingwood receberiam mais tarde (Freeman, 2007: 544).

Em 1923 Collingwood publicou sua primeira grande obra sobre a Bretanha Romana, Roman Britain. A obra ganhou uma segunda edição em 1932 e, ainda, outra revisão em 1949. A publicação expressava a posição de Collingwood a respeito da "Romanização", em parte influenciada pelos trabalhos de Haverfield, sem, contudo, ser especificamente crítico deles. Enquanto a primeira edição parecia enfatizar como a cultura romano-bretã havia se fundido de maneira satisfatória, a segunda edição apontava para falhas neste sincretismo cultural (Freeman, 2007: 546). A obra também foi elogiada por utilizar uma linguagem mais acessível ao leitor não especializado (Johnston, 1967: 39). O que fica claro no volume, especialmente nas revisões, é que Collingwood não acreditava mais na possibilidade de se comensurar a "romanização" da Bretanha:

não podemos simplesmente fazer a asserção de que a Bretanha foi Romanizada. ...De um acerto modo, poderia ser dito que a civilização da Bretanha Romana não era nem romana, nem celta, mas romano-bretã, uma fusão de duas coisas em uma que era diferente de ambas. Mas esta não é uma forma satisfatória de colocar as coisas já que sugere que houve uma amálgama definitiva de elementos romanos e celtas produzindo uma civilização que fosse consistente e homogênea. O fato é que uma escala de Romanização pode ser reconhecida. Em uma ponta dela estão as altas classes da sociedade e as cidades; na outra, as classes baixas e o campo. A aristocracia bretã foi rápida em adotar os costumes romanos, mas estes eram muito mais modelos da Gália Romana do que de Roma, especificamente. Contudo, esta civilização romano-celta gradualmente se torna menos romana e mais celta quando nos movemos das grandes cidades para as pequenas, no campo, para a pequena uilla do humilde proprietário de terras, e, finalmente, para os vilarejos. Aqui encontramos um stratum da população em cujas vidas o elemento romano dificilmente aparece; se devemos chamar sua civilização de romano-celta, seria somente cinco por cento romana e noventa e cinco celta (Collingwood, 1949: 91-2. Trad. do autor).

Fica bem demarcada na obra uma preocupação por parte de Collingwood em conectar e inserir os estudos da Bretanha Romana à história britânica. Para isso, dedicará grande atenção ao processo de saída dos romanos da ilha. Na edição de 1949 de Roman Britain, a suposta "derrocada" da cultura romana se deve muito mais à sua natureza de "fino verniz" do que às invasões bárbaras. A própria presença romana na ilha deixa de ser algo fortuito, e apresentará sua lógica própria (Collingwood, 1949: 12-3).

Em 1930, Collingwood publicou The Archaeology of Roman Britain. Para alguns, a obra mais influente de Collingwood na Arqueologia, sendo 
comparada ao seu sucesso na área da filosofia da História com The Idea of History (1946). O volume procurou abordar a "Romanização" da Bretanha de forma mais técnica, sem utilizar textos históricos, em uma tentativa de sintetizar os últimos cinquenta anos de estudos romano-bretões. Em larga medida, uma resposta à crescente profissionalização dos estudos da Bretanha romana. Foi, de modo geral, muito bem recebida pela crítica (Freeman 2007: 548).

A última das obras de Collingwood na área dos estudos romano-bretões foi publicada em 1936, reeditada em 1937, intitulada Roman Britain and the English Settlements, em parceria com J.N.L. Myres. É tida como a primeira obra a oferecer uma narrativa completa dos quatro séculos de ocupação romana na Bretanha, e recebeu críticas dissonantes. Avaliada por muitos com uma obra que apenas acrescentou atualizações aos dados já coletados anteriormente por Haverfield, Roman Britain and the English Settlements ainda foi acusada de ser um mero veículo às teorias filosóficas de Collingwood (Freeman, 2007: 550-1). Aqui, também, a "Romanização" é concebida como um processo dinâmico, não acontecendo linearmente. Todavia, Collingwood pressupõe que todo o Império romano teria passado pelo mesmo tipo de abordagem político-cultural, em algo que se configurava como uma intencionalidade lógica e de consenso, uniforme. Nisso Collingwood encontrava a maior diferença entre o Império romano e a realidade do Império Britânico de seu tempo, em especial na Índia e na África. Collingwood reconhecia que as comparações eram frequentes entre os dois impérios, mas se opunha às aproximações. Para ele, o Império Romano havia sido único. $O$ que chama nossa atenção na questão dos usos do passado e nas comparações entre Roma e o imperialismo britânico, é a crítica feita por Collingwood à obra de um contemporâneo de Collingwood, o influente escritor britânico Rudyard Kipling (1865-1936). Segundo A.R. Burn

Collingwood, seguindo Haverfield, gostava de enfatizar a total Romanização do Império Romano, o que fez da Gália e da Bretanha Romana algo bem diferente das províncias britânicas na Índia e na África. Ele foi particularmente duro com Kipling nas imagens de Puck of Pook's Hill sobre a concepção das divisões sociais da Índia baseadas na Bretanha Romana, com uma clara divisão entre romanos e "nativos". Nisto, ele tinha razão. Com todas as suas faltas, os romanos jamais traçaram tal divisão (1932: 66. Apud Freeman, 2007: 550. Trad. do autor).

De acordo com Parker (2000), Collingwood aplicou sua filosofia da História à interpretação dos vestígios materiais que analisou. Trata-se de sua forma de interpretar o passado por meio da recriação dos eventos do 
passado em sua própria mente, a empatia com a personagem histórica, não por meio da presunção de como ele ou ela pensava, mas antes, na total compreensão de seu objeto e de seu pensamento (Parker 2000: 166). Para Collingwood, toda ideia, (ou pergunta e resposta), é formulada em resposta a um problema específico. Para Freeman (2007), as consequências deste pensamento no campo da Arqueologia é que "cada objeto encontrado em um sítio há de ter servido a uma função ou propósito na vida de seu usuário e/ou habitante do sítio (p. 555)." De fato, à sua época, Collingwood sofreu as maiores críticas por ter, segundo alguns, manipulado dados arqueológicos para que se adequassem às suas soluções (idem). Hoje, a rigidez nos conceitos identitários apresentados por Collingwood em Roman Britain and the English Settlements acabou por ser seu aspecto mais duramente criticado. Termos como "celta", ou "romano", ou "romano-bretão" afloram na obra como elementos desprovidos de tensões internas, como monólitos. Collingwood reconheceu os limites da "Romanização", mas não chegou ao ponto de questionar seus inconsistentes e múltiplos significados, sua precariedade conceitual (Freeman 2007: 553).

\section{Conclusão}

Na visão mais aceita da linha de transmissão acadêmica dos estudos sobre a Bretanha Romana, a morte de Collingwood em 1943 transformou Ian Archibald Richmond (1902-1965) em seu sucessor e no novo líder das pesquisas. Seu trabalho tem sido respeitado como o de um grande arqueólogo e historiador, em uma linha sucessória que começa em Haverfield e passa por Collingwood (Birley, 1966: 302). É preciso notar que essa linha ressalta a tradição de Oxford, também, onde, aliás, o pensamento de Richmond continua a exercer uma grande influência em seus alunos. De fato, segundo alguns, mais do que sua obra, seu maior feito foi a criação de um sólido grupo de seguidores que vieram a ocupar grandes cargos nos centros acadêmicos britânicos, algo que Collingwood não teria logrado fazer (Freeman, 2007: 557, 564-5).

É bem verdade que hoje Collingwood é muito mais lembrado por seu trabalho na Filosofia da História, mas foi de seu trabalho na Arqueologia que retirou seus melhores estudos de caso (Hodder 1986: 90-102). Mesmo tendo diminuído sua atenção à Arqueologia, Collingwood nunca subestimaria totalmente sua própria contribuição aos estudos romanobretões. Especialmente sua dedicação ao $R I B$, a despeito de qualquer insatisfação que pudesse demonstrar com alguns de seus resultados. Em 
algo que só pode valorizar sua abordagem, seus interesses na Bretanha Romana se encontravam muito mais no meio rural e nas populações desprivilegiadas do que nos acampamentos militares, como fizera Haverfield (Freeman, 2007: 545). No campo interpretativo, seu olhar filosófico aliou-se às suas descrições precisas e ofereceram interpretações mais polissêmicas, por vezes (Richmond 1943: 254, contra Freeman 2007: 556). Alguns de seus modelos interpretativos das organizações das uillae permanecem em uso até hoje (Hingley, 2010: 61). Esse "colorido" arcabouço interpretativo e sua posição acadêmica híbrida - pois era filósofo, historiador e arqueólogo - renderam-lhe críticas muito duras que hoje merecem ser revistas. Considerado por alguns, hoje, como um "problema" aos estudos da Bretanha Romana, dada a sua grandeza acadêmica à época de suas publicações, sufocante, segundo Freeman (2007: 557-8), Collingwood parece sofrer muito mais com a avaliação extemporânea de seu temperamento do que de suas contribuições. Se procurava responder às suas perguntas pré-estabelecidas nos sítios escavados, e deixava "escapar" alguns fatos, como apontam seus críticos, parece estar muito mais próximo da realidade de outros arqueólogos de sua época do que se imagina (para uma visão mais apreciativa de Collingwood do que a de Freeman 2007, ver Leach 2009). Existe uma grande coerência em sua forma de avaliar o preconceito do historiador ao se aproximar de seu objeto e a maneira como lidava com suas fontes arqueológicas. Isso é pouco explorado por seus críticos. Seu ressurgimento na Arqueologia pós-processual pode ser, às vezes, ridicularizado, mas sua dedicação ao tema romano-bretão, e o fato de ter sido o único estudioso voltado a essa questão em sua época, com muitas escavações e publicações na área, não podem deixar de causar impacto e ganhar o devido reconhecimento.

\section{Agradecimentos}

Fico muito grato a Glaydson José da Silva, que organiza este dossiê, pelo convite para contribuir nessa homenagem ao Professor Pedro Paulo Funari. Aproveito, ainda, para parabenizá-los pela bela iniciativa. A responsabilidade por eventuais erros ou omissões no texto recai sobre o autor.

Referências bibliográficas 
BIRLEY, E. "Sir Ian Archibald Richmond 1902-1965". Proceedings of the British Academy 52, 1966, p. 293-302.

BURN, A. R. The Romans in Britain, an Anthology of Inscriptions. Londres: B. Blackwell, 1932. 2a. edição de 1969.

CHIPPINDALE, C. "Ambition, deference, discrepancy, consumption: the intellectual background to a post-processual archaeology". In: YOFFEE, N.; SHERRATT, A. (Org.) Archaeological theory: who sets the agenda? Cambridge: CUP, 1997, p. 27-36.

COBB, C. R. "Social Reproduction and the Long Durée in the Prehistory of the Midcontinental United States". In: Whitley, D.S. 1998. 199-216.

COLLINGWOOD, R. G. "Review of Haverfield 1924". Antiquaries Journal 4. 1924a, p. 435-7.

COLLINGWOOD, R. G. Roman Britain. Londres: OUP, 1923.

COLLINGWOOD, R. G. Roman Britain. Oxford: Clarendon Press, 1949.

COLLINGWOOD, R. G. The Archaeology of Roman Britain. Londres: Methuen, 1930.

COLLINGWOOD, R. G. The Idea of History. Oxford: Clarendon Press; Oxford: OUP, 1946. Edição de 1993.

COLLINGWOOD, R. G. The Principles of History. Oxford: OUP, 1999.

COLLINGWOOD, R. G.; MYRES, J.N.L. Roman Britain and the English Settlements, Oxford: Clarendon Press. Segunda edição, 1937.

COLLINGWOOD, R. G.; MYRES, J.N.L. Roman Britain and the English Settlements, Oxford: Clarendon Press. Segunda edição, 1937.

COLLINGWOOD, R. G.; WRIGHT, R. P. The Roman Inscriptions of Britain, vol. I. Oxford: OUP, 1965.

COLLINGWOOD, R.G. Speculum Mentis. Oxford: Clarendon Press, 1924b.

COLLINGWOOD, R.G. The New Leviathan. Oxford: Clarendon Press, 1942. Edição de 1992. 
COLLINGWOOD, R.G.; MYRES, J.N.L. Roman Britain and the English Settlements, Oxford: Clarendon Press. Segunda edição, 1937.

FREEMAN, P. W. M. (1997) "Mommsen to Haverfield: the origins of studies of Romanization in late 19th-c. Britain". In: MATTINGLY, D. J. ed., 1997. 27-50.

FREEMAN, P. W. M. The Best Training-Ground for Archaeologists - Francis Haverfield and the Invention of Romano-British Archaeology. Oxford: Oxbow Books, 2007.

FUNARI, P. P. A. (1998) “Arqueologia, História e Arqueologia Histórica no Contexto Sul-Americano". In: Funari, P.P.A. org. (1998) Cultura Material e Arqueologia Histórica. Campinas: Coleção Idéias, 1998, p. 7-34.

FUNARI, P. P. A. "Bretanha Romana". Revista de Historia da Arte e Arqueologia 1. Campinas: UNICAMP, 1994, p. 249-52.

FUNARI, P. P. A. "Dressel 20 amphora inscriptions found at Vindolanda: the reading of the unpublished evidence." V.A. Maxfield; M. J. Dobson (Org.) Roman Frontier Studies 1989. Exeter: University of Exeter Press, 1991, p. 65-72.

GILMAN, A. "Resposta a T. K. Earle e R. W. Preucel". In: "Processual Archaeology and the Radical Critique". Current Anthropology 28(4), 1987, 516.

GRAHAME, M. "Material culture and Roman identity: the spatial layout of Pompeian houses and the problem of ethnicity". In: LAURENCE, R. e J. Berry (Org.) Cultural Identity in the Roman Empire, Londres: Routledge, 1998, 156-78.

HERSKOVITS, M. J. The Myth of the Negro Past. Nova Iorque: Harper \& Brothers Publishers, 1941.

HILLS, C. "Historical Archaeology and Text" In: RENFREW, C.; BAHN, P. (Org.) Archaeology: The Key Concepts. Oxon: Routledge, 2005a, p. 137-41.

HINGLEY, R. “O Campo na Bretanha Romana: o significado das formas de assentamento rural". In: HINGLEY, Richard. O Imperialismo Romano: Novas perspectivas a partir da Bretanha. Trad. de Luciano César Garcia Pinto. Organização de Renata Senna Garraffoni, Pedro Paulo A. Funari e Renato Pinto. São Paulo: Annablume, 2010, p. 49-66. 
HINGLEY, R. "Resistance and domination: social change in Roman Britain". In: MATTINGLY, D.J. (Org.) Dialogues in Roman Imperialism. Power, discourse and discrepant experience in the Roman Empire. JRS (suplemento 23), Portsmouth: RI, 1997a, p. 81-100.

HINGLEY, R. "The 'legacy' of Rome: the rise, decline, and fall of the theory of Romanization". In: Jane Webster e Nicholas J. Cooper (Org.) Roman Imperialism: Post-Colonial Perspectives. Leicester: Leicester Archaeology Monographs 3, 1996, p. 35-48.

HINGLEY, R. Roman Officers and English Gentlemen. The Imperial Origins of Roman Archaeology. Londres: Routledge, 2000.

HODDER, I. Reading the Past: Current Approaches to Interpretation in Archaeology. Cambridge: CUP, 1986.

JENKINS, K. Re-thinking History, Londres: Routledge, 1991.

JOHNSTON, W. M. The Formative Years of R. G. Collingwood. The Hague Martinus Nijhoff, 1967.

JONES, S. "Historical categories and the praxis of identity: the interpretation of ethnicity in historical archaeology". In: FUNARI, P. P. A.; M. Hall, Siân Jones (Org.) Historical Archaeology: Back from the Edge. Londres: Routledge, 1999, p; 219-32.

JONES, S. The Archaeology of Ethnicity: Constructing identities in the past and present. Londres: Routledge, 1997.

KOHL, P. L. "Limits to a post-processual archaeology (or, The dangers of a new scholasticism)". In: YOFFEE, N.; SHERRATT, A. (Org.) Archaeological theory: who sets the agenda? Cambridge: CUP, 1997, p. 13-9.

LEACH, S. "An appreciation of R. G. Collingwood as an Archaeologist". Bulletin of the History of Archaeology 19(1), maio de 2009.

MATTINGLY, D. J. Dialogues of power and experience in the Roman Empire". In: Mattingly D. J, 1997b, p. 7-24.

MATTINGLY, D.J. (Org.) Dialogues in Roman Imperialism. Power, discourse and discrepant experience in the Roman Empire. JRS (suplemento 23), Portsmouth: RI, 1997a. 
MILLER, M.C. Athens and Persia in the Fifth Century BC: A Study in Cultural Receptivity. Cambridge: CUP, 1997.

MILLETT, M. The Romanization of Britain: An essay in Archaeological Interpretation. Cambridge: CUP, 1992.

PARKER C. The English Idea of History from Coleridge to Collingwood. Ashgate: Aldershot and Brookfield, VT, 2000.

PEEBLES, C. S. Annalistes, Hermeneutics and Positivists. In: Whitley, D.S. (1998). 2005, p. 183-97.

PINTO, R. Duas Rainhas, um Príncipe e um Eunuco: masculino e feminino nos estudos sobre a Bretanha Romana. São Paulo: Annablume, 2016.

RENFREW, C. "Cognitive Archaeology." In: RENFREW, C.; BAHN, P. (Org.) Archaeology: The Key Concepts. Oxon: Routledge, 2005a, p. 41-5.

RENFREW, C.; BAHN, P. (Org.) Archaeology: The Key Concepts. Oxon: Routledge, 2005a.

RENFREW, C.; BAHN, P. “Introduction.” In: Renfrew \& Bahn, 2005b, p. xi-xiv.

RICHMOND, I. A. "Robin George Collingwood". Archeology Aeliana 4 XIX. 1943, p. 254-5.

RIDLEY, Aaron. R. G. Collingwood: uma Filosofia da Arte. São Paulo: Editora UNESP. Trad. de José Oscar da Almeida Marques, 2001.

SALWAY, P. Roman Britain. Oxford: OUP, 1984.

SHANKS, M.; HODDER, I. "Processual, postprocessual and interpretive archaeologies". In: Whitley, D.S. (1998), 1988, p. 69-95.

SHANKS, M.; TILLEY, C. Re-Constructing Archaeology. Londres: Routledge. $2^{\mathrm{a}}$ ed, 1992.

VEYNE, P. Como se Escreve a História. Brasília: Ed. UnB, 1982.

WHITLEY, D. S. "New Approaches to Old Problems: Archaeology in Search of an Ever Elusive Past". In: Whitley D. S. 1998b, p. 1-28. 
WHITLEY, D.S. (Org.) Reader in Archaeological Theory: Post-Processual and Cognitive Approaches. Londres: Routledge, 1998a.

WYLIE, A. "A proliferation of new archaeologies: 'Beyond objectivism and relativism'". In: YOFFEE, N.; SHERRATT, A. (Org.) Archaeological theory: who sets the agenda? Cambridge: CUP. 1997, p. 20-6.

YOFFEE, N.; SHERRATT, A. (Org.) Archaeological theory: who sets the agenda? Cambridge: CUP. 1997. 